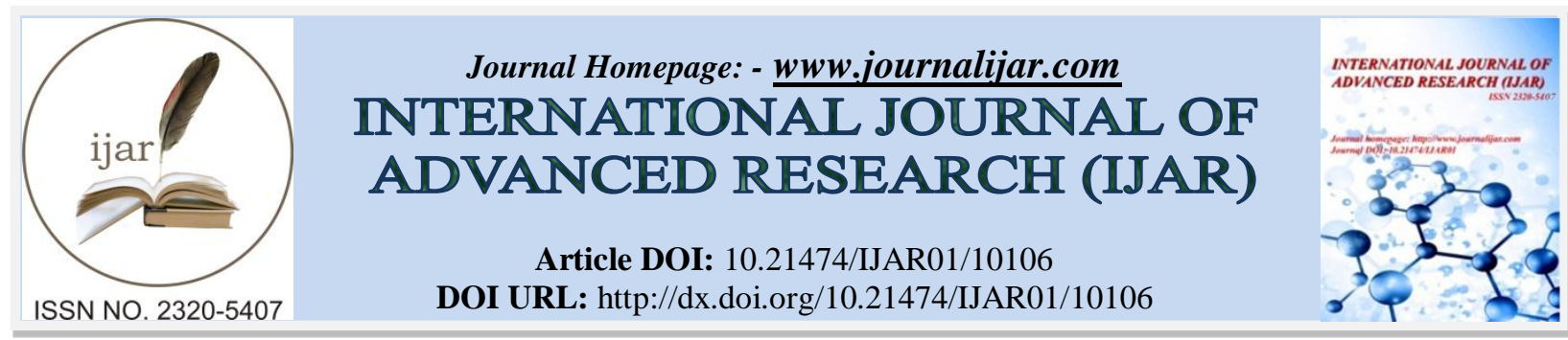

RESEARCH ARTICLE

\title{
AMELIORATIVE EFFECT OF CURCUMIN AGAINST HEPATORENAL ADVERSE EFFECTS OF CEFEPIME IN RATS.
}

Mossad G.A. Elsayed ${ }^{1}$, Enas A.H. Farag ${ }^{2}$ and Hala E.M. Abo Elfetouh ${ }^{3}$.

1. Department of Pharmacology, Faculty of Veterinary Medicine, Moshtohor, Toukh, Elqaliobiya, Egypt.

2. Department of Pharmacology, Animal Health Research Institute Benha branch, Benha, Egypt.

3. Pharmacist at Benha University Hospital, Benha, Egypt.

\section{Manuscript Info}

\section{Manuscript History}

Received: 14 September 2019

Final Accepted: 16 October 2019

Published: November 2019

Key words:-

Antibiotics, cefepime, cephalosporins,

curcumin, hepatotoxicity,

nephrotoxicity.

\begin{abstract}
Background: To examine the ameliorative effect of curcumin against the hepatorenal adverse effects of cefepime in rats.

Methods: A total of 48 albino rats were divided into four groups, each of 12 rats. Group one was considered as a control and was administered saline solution. Group two was the cefepime-treated group (45 $\mathrm{mg} / \mathrm{b}$.wt. intramuscularly) once daily for five consecutive days. Group three was the curcumin-treated group ( $200 \mathrm{mg} / \mathrm{b}$.wt. orally) once daily for five consecutive and group four was pretreated with curcumin followed by cefepime once daily for five consecutive days as above. Blood samples and liver and kidneys specimens were collected on the first, $7^{\text {th }}$ and $14^{\text {th }}$ day post treatment for serum biochemical assessment and histopathological examinations.

Results: Cefepime-treated rats showed significant $(P \leq 0.05)$ increases in serum levels of aspartate aminotransferase, alanine aminotransferase, total bilirubin, total protein and albumin suggesting liver damage. There were also significant $(P \leq 0.05)$ increases in the serum levels of urea and creatinine suggesting alterations of kidney functions. The alterations in serum biochemical parameters were associated with histopathological changes in liver and kidney. These alterations could successfully be ameliorated by pretreatment with curcumin.

Conclusion: Results suggest a possible contribution of cefepime in hepatic and nephrotoxicity with apparent biochemical and histopathological alterations. Therefore, patient renal function and liver function should be monitored before and during cefepime therapy. Pretreatment with curcumin could limit the adverse effect of cefepime on liver and kidneys.
\end{abstract}

Copy Right, IJAR, 2019,. All rights reserved.

\section{Introduction:-}

Drug-induced hepatorenal injury is a frequent adverse event which contributes to morbidity and increased healthcare utilization. Cephalosporins are well-known to induce organ damage in both animals and humans. Cefepime is a new parenteral fourth-generation cephalosporin which holds promise for management of severe infections. ${ }^{1}$ Cefepime spectrum is very large, being very active against Gram-negative bacilli: Enterobacter, Pseudomonas aeruginosa,

Corresponding Author:-Mossad G.A. Elsayed.

Address:-Department of Pharmacology, Faculty of Veterinary Medicine, Moshtohor, Toukh, Elqaliobiya, Egypt. 
Klebsiella pneumoniae, Serratia, Citrobacter, Proteus mirabilis and Gram-positive cocci: Staphylococcus aureus mainly methicillin-susceptible strains Streptococcus pneumoniae, Streptococcus pyogenes. ${ }^{2}$ Cefepime is the best choice in life threatening nosocomial infections occurring in patients in the intensive care units. ${ }^{3}$ It is widely used in hospital for its satisfactory success in the treatment of pneumonia, bacteremia, neutropenia, urinary tract, abdominal, skin and soft tissue infections. ${ }^{4}$ Cefepime exerts its bactericidal action via interfering with peptidoglycan synthesis and through the activation of bacterial Murin and lysin. ${ }^{3}$ Administration of cefepime was reported to induce nephrotoxicity ${ }^{5}$ and liver injury. ${ }^{6}$ Therefore, extended information concerning cefepime adverse effect on liver and kidney will be of great beneficial effect for both physicians and patients.

Curcumin, the main yellow pigment in turmeric (Curcuma longa), is broadly used as a spice and coloring agent in many foods, cosmetics and pharmaceutical industries. Curcumin has been shown to protect from hepatorenal damage $^{7-10}$ and possesses anti-tumor, antioxidant, anti-inflammatory, antimicrobial, and gastroprotective activities against toxic chemicals. ${ }^{11}$ Most of these benefits can be attributed to its antioxidant and anti-inflammatory effects.

To our knowledge, there is no data concerning amelioration of the hepatic and renal adverse effects of cefepime by curcumin. Therefore, in the present work, we have investigated the possibility that curcumin may be effective in ameliorating or preventing cefepime-induced hepatorenal adverse effects.

\section{Materials And Methods:- \\ Drugs and chemicals}

Cefepime (Maxipime ${ }^{\circledR}$ ) was obtained as cefepime hydrochloride and L-arginine from Smith Kline Beecham pharmaceutical Co., Cairo, Egypt as a sterile powder for intravenous or intramuscular injection. The drug was dissolved in distilled water before administration. Curcumin oil was purchased from El-Captain Company for extracting herbs, natural oils and cosmetics, El-Obour City, Cairo, Egypt. All assay kits (Biodiagnostics Co., Cairo, Egypt) were used. All other reagents used were of analytical grade.

\section{Experimental rats}

A total of 48 male Wister albino rats weighing 200-250 g and of 50 60 days age was used in the experimental investigation of this study. These rats were obtained from the animal house of Faculty of Veterinary Medicine, Benha University, Egypt. Animals were housed in $49 \times 35 \mathrm{~cm}$ stainless steel wire mesh cages with bedding of ground wood chips at standard temperature and humidity. They were fed on fresh food and water was provided ad libitum. Rats were kept at constant nutritional and environmental conditions throughout experiment. The rats were left for 15 days for adaptation and acclimatization before starting the experiment. The experiments were carried out in accordance with the guidelines set by the Ethical Committee of Faculty of Veterinary Medicine, Benha University, Egypt. All efforts were followed to minimize pain to rats.

\section{Experimental design}

The rats were randomly allocated into four equal groups, each of 12 rats. Group one (control) was administered normal saline intramuscularly daily for 5 consecutive days. Group two were administered cefepime $45 \mathrm{mg} / \mathrm{kg} \mathrm{b}$. wt ${ }^{5}$ (less than the rat's lethal dose $50 \%$ (LD50), which is $1272 \mathrm{mg} / \mathrm{kg}$ ) intramuscularly daily for 5 consecutive days. Rats of group three were administered curcumin oil $200 \mathrm{mg} / \mathrm{kg} \mathrm{b.wt}{ }^{12}$ orally daily for 5 consecutive days. Rats of group four were pretreated with $200 \mathrm{mg} / \mathrm{kg}$ b.wt curcumin orally for 5 consecutive days followed by $45 \mathrm{mg} / \mathrm{kg} \mathrm{b}$.wt cefepime intramuscularly daily for 5 consecutive days.

\section{Blood sampling}

After last administration, under isoflurane anesthesia, blood samples were taken from four rats at the first, $7^{\text {th- }}$ and $14^{\text {th }}$ day post treatment from the median canthus of the eye and allowed to clot. Clear serum samples were separated by centrifugation at 1600 $\mathrm{g}$ for $15 \mathrm{~min}$ at $4^{\circ} \mathrm{C}$ and used later for biochemical analysis of serum transaminase activities (AST and ALT) ${ }^{13}$, alkaline phosphatase (ALP) ${ }^{14}$, total bilirubin ${ }^{15}$, albumin ${ }^{16}$, total protein ${ }^{17}$, serum creatinine ${ }^{18}$ and serum urea. ${ }^{19}$

\section{Histopathology of liver and kidneys}

The liver and kidney specimens were taken from of rats immediately after sacrificing at the first, $7^{\text {th- }}$ and $14^{\text {th- }}$ day post last treatment and washed by normal saline and fixed in $10 \%$ formalin for $24 \mathrm{~h}$. Specimens were embedded into paraffin at 56 degrees in a hot air oven for $24 \mathrm{~h}$. Paraffin bees wax tissue blocks were prepared for sectioning at 5 microns thickness by using sledge microtome. The obtained tissue sections were loaded on glass slides, deparaffinized and stained by hematoxylin and eosin stain for their routine examination under light microscope. ${ }^{20}$ 


\section{Statistical Analysis:-}

Statistical analysis was conducted with the Statistical Package for Social Science (Version 16; SPSS Inc., Chicago, IL, USA) to determine if variables differed between groups, according to Snedecor and Cochran, (1989). ${ }^{21}$ The Shapiro-Willk test was used to test the normal distribution of the data before statistical analysis was performed. Comparison between means was conducted by one-way ANOVA and subsequent Duncan's multiple ranges test. ${ }^{22}$ Data were expressed as mean $\pm \mathrm{SE}$, $(\mathrm{n}=12)$. Probability values of less than $0.05(\mathrm{P} \leq 0.05)$ were considered significant.

\section{Results:-}

In the present study cefepime-treated rats showed significant alterations in liver biochemical parameters. Cefepime induced significant $(\mathrm{P} \leq 0.05)$ elevations in serum ALT, AST, ALP, and total bilirubin (Fig. 1). On the other hand, there were significant decrease in serum albumin and total protein levels (Fig. 2). These alterations were ameliorated by curcumin pretreatment. Furthermore, cefepime-treated rats showed significant alterations in kidney biochemical parameters as it triggered significant $(\mathrm{P} \leq 0.05)$ increases in serum creatinine and urea level as compared to the control group, which were diminished by curcumin pretreatment (Table 1 and 2, respectively). Cefepime administration induced hepatic and renal histopathological changes as shown in fig. $3 \mathrm{~A}$ and $4 \mathrm{~A}$, respectively. However, the pretreatment with curcumin has ameliorated cefepime-induced histopathological alterations and the liver and the kidney regained their normal activity (fig. $3 \mathrm{~B}$ and $4 \mathrm{~B}$, respectively).

Fig 1:-Effect of cefepime ( $45 \mathrm{mg} / \mathrm{kg}$ b. wt.) administered intramuscularly for 5 days, curcumin $(200 \mathrm{mg} / \mathrm{kg} \mathrm{b}$. wt.) given orally for 5 days and curcumin orally followed by cefepime intramuscularly for 5 days on serum ALT (A),

AST (B), ALP (C), and bilirubin (D) levels (U/L) at the $1^{\text {st }}, 7^{\text {th }}$ and $14^{\text {th }}$ day after last treatment, compared with control level in rats $(n=12)$. Mean values with different letters within the same column are statistically significant at $(\mathrm{P} \leq 0.05)$. G1; control group; G2: cefepime-treated group; G3: curcumin-administered group; G4: curcumincefepime-treated group.
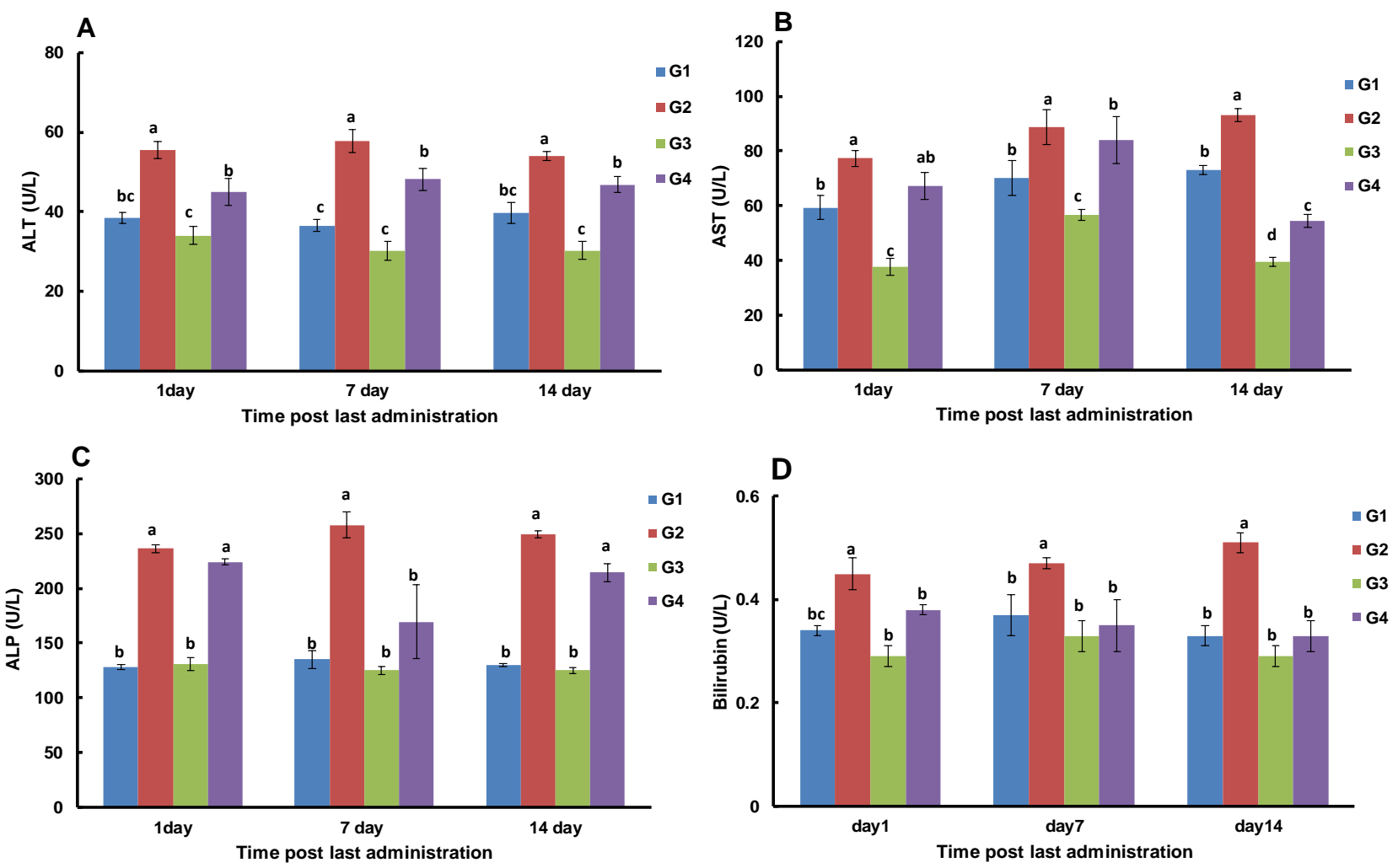

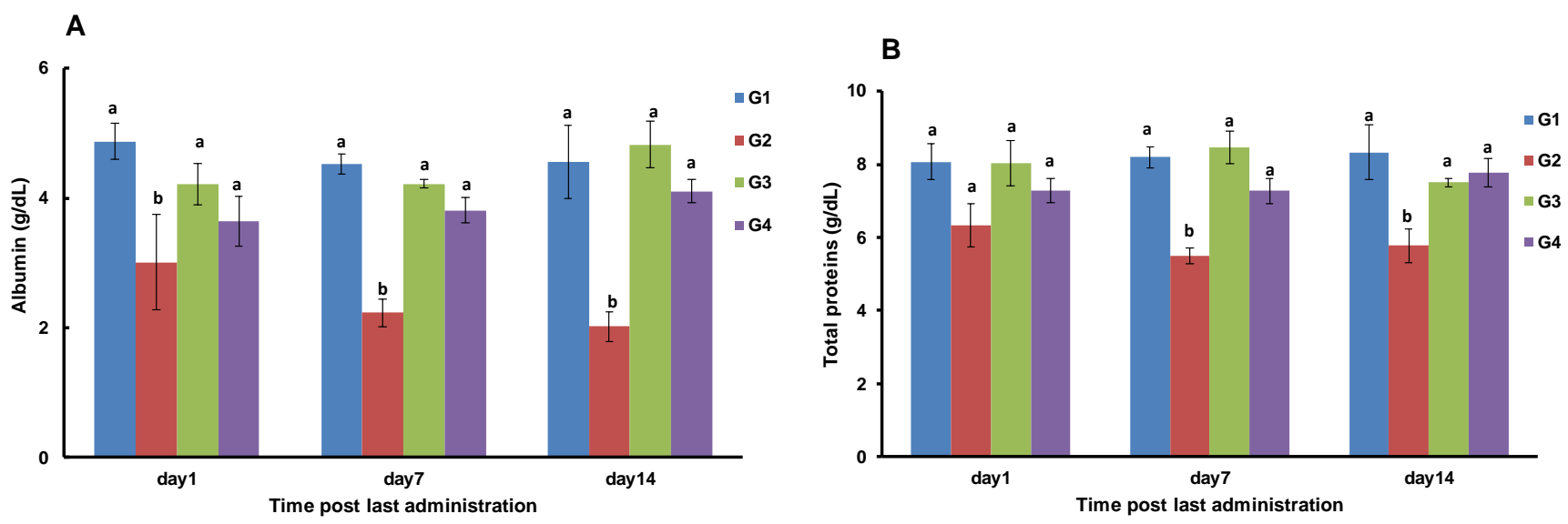

Fig 2:-Effect of cefepime ( $45 \mathrm{mg} / \mathrm{kg} \mathrm{b}$. wt), administered intramuscularly for 5 days, curcumin $(200 \mathrm{mg} / \mathrm{kg} \mathrm{b}$. wt.), given orally for 5 days and curcumin orally followed by cefepime intramuscularly for 5 days on serum albumin (A) and total protein (B) levels $(\mathrm{g} / \mathrm{dl})$ at the $1^{\text {st }}, 7^{\text {th }}$ and $14^{\text {th }}$ day after last treatment, compared with control level in rats $(\mathrm{n}=12)$. Mean values with different letters within the same column are statistically significant at $(\mathrm{P} \leq 0.05)$. $\mathrm{G} 1$; control group; G2: cefepime-treated group; G3: curcumin-administered group; G4: curcumin-cefepime-treated group.

Table 1:-Effect of cefepime ( $45 \mathrm{mg} / \mathrm{kg} \mathrm{b}$. wt), administered intramuscularly for 5 days, curcumin $(200 \mathrm{mg} / \mathrm{kg} \mathrm{b}$. wt.), given orally for 5 days and curcumin orally followed by cefepime intramuscularly for 5 days on serum urea level $(\mathrm{mg} / \mathrm{dl})$ at the $1^{\text {st }}, 7^{\text {th }}$ and $14^{\text {th }}$ day after last treatment, compared with control level in rats $(\mathrm{n}=12)$.

\begin{tabular}{|l|l|l|l|}
\hline \multirow{2}{*}{ Animal group } & Time after last administration & \multicolumn{2}{|l|}{} \\
\cline { 2 - 4 } & day1 & day7 & day14 \\
\hline Control & $19.8 \pm 0.87^{\mathrm{c}}$ & $20.8 \pm 0.63^{\mathrm{c}}$ & $19.3 \pm 0.64^{\mathrm{c}}$ \\
\hline Cefepime & $32.3 \pm 1.71^{\mathrm{a}}$ & $35.5 \pm 1.07^{\mathrm{a}}$ & $38.3 \pm 1.95^{\mathrm{a}}$ \\
\hline Curcumin & $19.8 \pm 1.05^{\mathrm{c}}$ & $20.1 \pm 0.62^{\mathrm{c}}$ & $21.3 \pm 1.05^{\mathrm{c}}$ \\
\hline Curcumin+ cefepime & $23.2 \pm 1.69^{\mathrm{b}}$ & $24.5 \pm 1.37^{\mathrm{b}}$ & $22.0 \pm 0.64^{\mathrm{b}}$ \\
\hline
\end{tabular}

Mean values with different letters within the same column are statistically significant at $(\mathrm{P} \leq 0.05)$.

Table 2:-Effect of cefepime ( $45 \mathrm{mg} / \mathrm{kg} \mathrm{b}$. wt), administered intramuscularly for 5 days, curcumin $(200 \mathrm{mg} / \mathrm{kg} \mathrm{b}$. wt.), given orally for 5 days and curcumin orally followed by cefepime intramuscularly for 5 days on serum creatinine level $(\mathrm{mg} / \mathrm{dl})$ at the $1^{\text {st }}, 7^{\text {th }}$ and $14^{\text {th }}$ day after last treatment, compared with control level in rats $(\mathrm{n}=12)$.

\begin{tabular}{|l|l|l|l|}
\hline \multirow{2}{*}{ Animal group } & \multicolumn{3}{|l|}{ Time after last administration } \\
\cline { 2 - 4 } & day1 & day7 & day14 \\
\hline Control & $0.84 \pm 0.04^{\mathrm{b}}$ & $0.84 \pm 0.09^{\mathrm{b}}$ & $0.81 \pm 0.05^{\mathrm{b}}$ \\
\hline Cefepime & $1.85 \pm 0.27^{\mathrm{a}}$ & $1.5 \pm 0.24^{\mathrm{a}}$ & $1.04 \pm 0.21^{\mathrm{a}}$ \\
\hline Curcumin & $0.86 \pm 0.03^{\mathrm{b}}$ & $0.86 \pm 0.12^{\mathrm{b}}$ & $0.78 \pm 0.02^{\mathrm{b}}$ \\
\hline Curcumin+ cefepime & $0.90 \pm 0.08^{\mathrm{b}}$ & $0.88 \pm 0.01^{\mathrm{b}}$ & $0.79 \pm 0.08^{\mathrm{b}}$ \\
\hline
\end{tabular}

Mean values with different letters within the same column are statistically significant at $(\mathrm{P} \leq 0.05)$. 

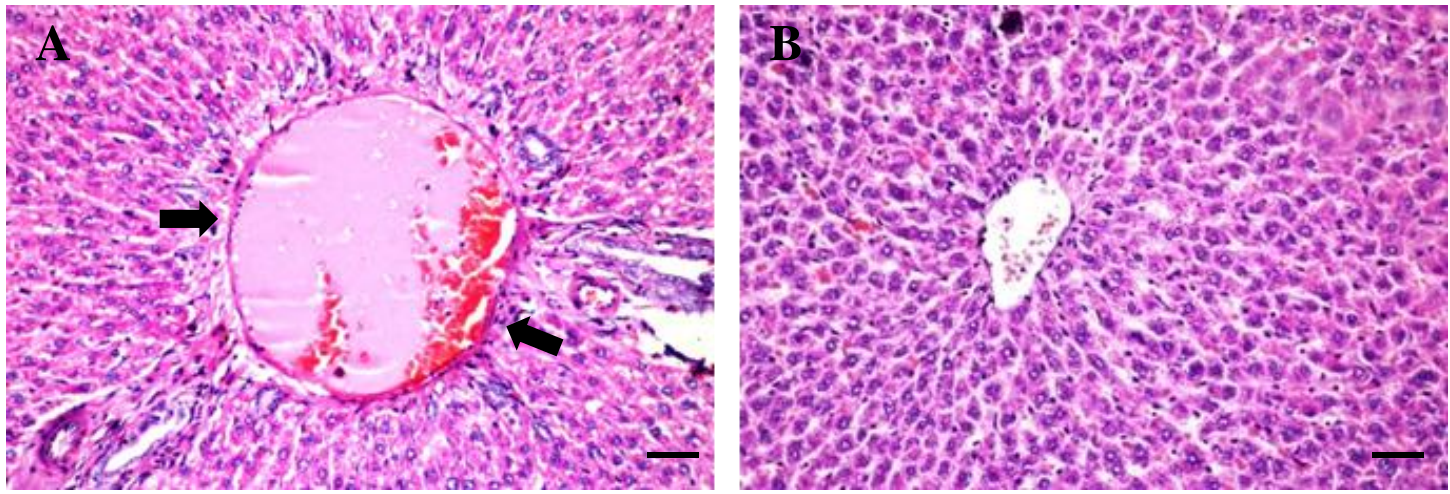

Fig 3:-Liver of cefepime-treated rats showing degeneration in hepatocytes surrounding and adjacent to the portal area with fatty changes and dilatation and congestion on the portal vein with focal hemorrhage in the parenchyma associated with multiple newly formed bile ductulus (A, indicated by black arrow). However, a of curcumin pretreatment (B) could successfully protect the liver from these alterations (H\&E, x40, bar 50).
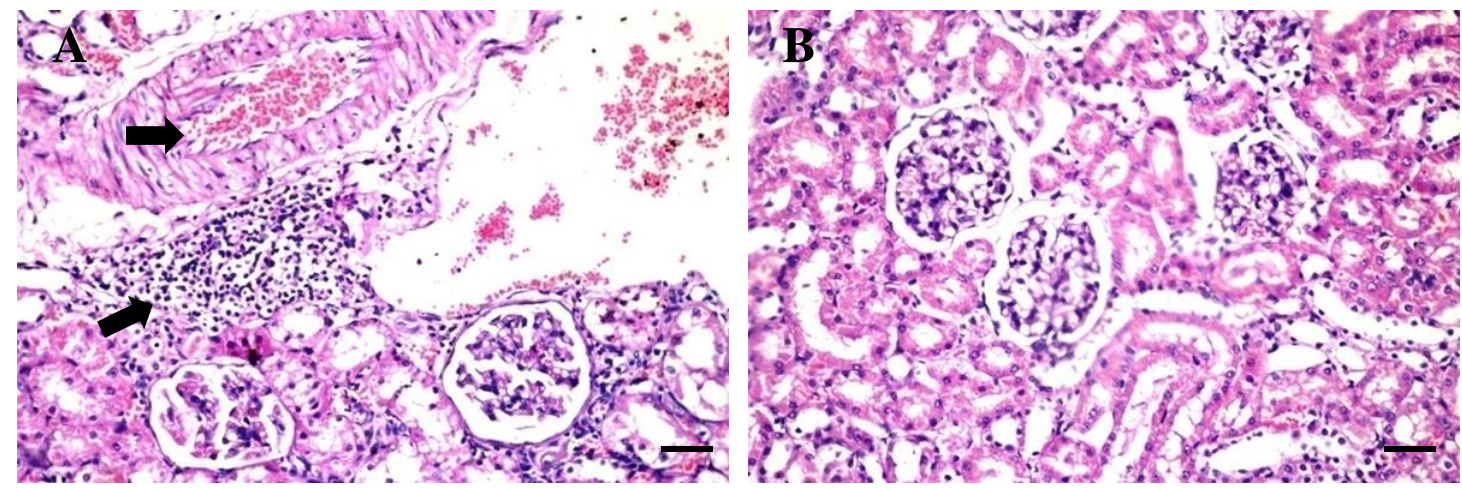

Fig 4:-Kidney of cefepime-treated rats showing focal inflammatory cells infiltration in between the dilated and congested blood vessels and renal tubules as well as glomeruli. Degeneration in tubular lining epithelium with congestion of intratubular blood vessels at the cortex was also noticed (A, black arrow). However, curcumin pretreatment could successfully protect the kidneys (B) from these alterations (H\&E, x40, bar 50).

\section{Discussion:-}

Liver and kidney are vital organs that have multidimensional functions that support every other organ of the body. They are the main organs for elimination and metabolism of drug and xenobiotics. Most antibiotics have adverse effects on liver and kidney. Cephalosporins have a great potential to cause nephrotoxicity and to somewhat hepatic toxicity. Being a cephalosporin antibiotic, cefepime may have the probability to induce nephrotoxicity and hepatotoxicity. The earlier detection of nephrotoxicity and hepatotoxicity may protect the kidney and the liver from a probable irreversible renal and hepatic damage. To our knowledge most studies of cefepime adverse effects concentrated on its neurotoxicity and until now there is a shortage in data concerning cefepime hepatic and nephrotoxicity. Therefore, the present study aimed to detect nephrotoxic and hepatotoxic potentials of cefepime to help both physician and patients to keep these vital organs in a good healthy condition.

In the present study, cefepime treated rats showed elevated aspartate transaminase, alanine transaminase and alkaline phosphatase, suggesting liver cell injury that led to the leakage of these enzymes to blood. Similar result reported cefepime induced liver injury ${ }^{6}$. Other cephalosporins, ceftriaxone ${ }^{23}$, cefixime ${ }^{24}$, cefazolin ${ }^{25}$, cefpirome ${ }^{26}$ were reported to induce liver damage with subsequent elevation of liver enzymes.

Cefepime-treated rats also showed a significant increase in total bilirubin level which reflect the disability of the liver to remove it, hence alteration on liver function. Hyperbilirubinemia is an indicator of hepatotoxicity or gallbladder disorders. These results come in agreement with the results which stated the occurrence of hyperbilirubinemia following ceftriaxone therapy. ${ }^{27,28}$ 
Our data showed that the total protein and albumin were significantly declined. This hypoalbuminemia may be due to liver cell damage as the liver is the main manufacturer of albumin or it might be due kidney function disorders which affect the reabsorption of protein mainly albumin via the kidney during glomerular filtration. The results come in agreement with those previously stated a possible contribution of cefepime in proteinuria due to nephritic disorders. ${ }^{5}$ Ceftriaxone was reported previously to induce reduced total protein and albumin level. ${ }^{29}$

The significant increases in serum creatinine and serum urea levels indicated impaired renal function in filtration of waste products attributed to renal insufficiency which may be due to vacuolization of glomerular tuft and degeneration of renal tubules. ${ }^{30}$ Cefepime treated rats also showed significant increase urea and creatinine levels in serum which may reflect reduction on glomerular filtration. The obtained results come in agreement with the results which reported acute interstitial nephritis and dress syndrome without eosinophilia in cefepime treated patient. ${ }^{31}$ Another similar result stated that cefepime was able to induce pyuria and impaired renal function. ${ }^{32}$ Cefotaxime was reported to produce a significant elevation in creatinine, urea, sodium, potassium, calcium concentrations. ${ }^{33}$ Cefepime and cefpirome were reported to be nephrotoxic but cefpirome was reported to increase the average value of serum creatinine to higher extent. ${ }^{34}$

Cefepime-treated rats showed abnormal histopathology of liver and the kidneys. The liver showed severe dilatation and congestion on the portal vein with multiple moveable bile ductulus on portal area, certain degree of degeneration on hepatocytes occurred. The results come in agreement with that obtained previously. ${ }^{6}$ Cefotaxime was reported previously to produce hematological and histopathological disorders in liver. ${ }^{33}$. Focal area of coagulative necrosis on the liver cell was reported with cefepime. ${ }^{35}$

The kidney of cefepime-treated rats showed degeneration on tubular lining epithelium and congestion on tubular blood vessels. These results come in agreement with those previously reported. ${ }^{36}$ Cefepime was reported to produce renal tubular, glomerular and vascular changes. ${ }^{5}$ Cefotaxime and ceftiofur were reported to exhibit histopathological alteration on the liver and kidney tissue on rats. ${ }^{37}$ Renal blood vessels congestion accompanied by perivascular edema were reported with cefepime. ${ }^{35}$

In the present study rats pretreated with curcumin followed by cefepime showed amelioration of biochemical disorders; aspartate aminotransferase, alanine aminotransferase, alkaline phosphatase returned to normal value. Plasma protein alteration was restored, and the liver regained its normal function and histology. These results come in agreement with those reported that curcumin was able to correct liver damage caused by aflatoxin $\mathrm{B} 1^{38}$, meloxicam in rats ${ }^{39}$ and gentamicin nephrotoxicity and hepatotoxicity in guinea pig. ${ }^{40}$ Another similar result reports the palliative action of curcumin in iron-induced hepatotoxicity ${ }^{41}$, and ethanol induced hepatotoxicity ${ }^{42}$ in rats. Curcumin was reported to reverse the alteration of paracetamol induced hepatotoxicity and nephrotoxicity in rats. ${ }^{43}$, ${ }^{44}$ Curcumin was previously reported to correct gentamicin induced nephrotoxicity ${ }^{45}$, doxorubicin nephrotoxicity ${ }^{46}$ in rats. The histopathological alterations that were altered in the kidney by lithium were successfully corrected by coadministration of curcumin. ${ }^{47}$ Degenerated epithelial lining in convoluted tubules, degenerated glomerulus and perivascular infiltrations of inflammatory cells, caused by gentamicin were reported to be corrected by curcumin. ${ }^{40}$

\section{Conclusion:-}

Cefepime can induce some hepatotoxic effect and nephrotoxic effect in rats that could be ameliorated by pretreatment with curcumin.

\section{Funding:}

No funding sources.

\section{Conflict of interest:}

None declared.

The manuscript has been read and approved by all the authors which contributed equally to this work.

\section{References:-}

1. Elsayed MGA, Elkomy AAA, Elbadawy M. Some Pharmacodynamic Aspects of Cefepime. Journal of Pharmaceutics. 2013;2013:10. 
2. Yahav D, Paul M, Fraser A, Sarid N, Leibovici L. Efficacy and safety of cefepime: a systematic review and meta-analysis. The Lancet Infectious diseases. 2007;7(5):338-348.

3. Angelescu M, Apostol A. [Cefepime (maxipime), large spectrum 4th generation cephalosporin, resistant to beta-lactamases]. Chirurgia (Bucharest, Romania : 1990). 2001;96(6):547-552.

4. Chapman TM, Perry CM. Cefepime: a review of its use in the management of hospitalized patients with pneumonia. American journal of respiratory medicine : drugs, devices, and other interventions. 2003;2(1):75107.

5. Elsayed MGA, Elkomy AAA, Gaballah MS, Elbadawy M. Nephrotoxicity of cefepime: A new cephalosporin antibiotic in rats. J Pharmacol Pharmacother. 2014;5(1):33-38.

6. Liao P-F, Wu Y-K, Huang K-L, Chen H-Y. A rare case of cefepime-induced cholestatic liver injury. Ci Ji Yi Xue Za Zhi. 2019;31(2):124-128.

7. Cekmen M, Ilbey Y, Ozbek E, Simsek A, Somay A, Ersoz C. Curcumin prevents oxidative renal damage induced by acetaminophen in rats. Food and chemical toxicology : an international journal published for the British Industrial Biological Research Association. 2009;47:1480-1484.

8. Kheradpezhouh E, Panjehshahin M-R, Miri R, et al. Curcumin protects rats against acetaminophen-induced hepatorenal damages and shows synergistic activity with $\mathrm{N}$-acetyl cysteine. European Journal of Pharmacology. 2010;628(1):274-281.

9. Lee HY, Kim SW, Lee GH, et al. Turmeric extract and its active compound, curcumin, protect against chronic CCl4-induced liver damage by enhancing antioxidation. BMC complementary and alternative medicine. 2016;16(1):316.

10. Lee G-H, Lee H-Y, Choi M-K, Chung H-W, Kim S-W, Chae H-J. Protective effect of Curcuma longa L. extract on CCl(4)-induced acute hepatic stress. BMC Res Notes. 2017;10(1):77-77.

11. Hosseini A, Hosseinzadeh $\mathrm{H}$. Antidotal or protective effects of Curcuma longa (turmeric) and its active ingredient, curcumin, against natural and chemical toxicities: A review. Biomedicine \& pharmacotherapy $=$ Biomedecine \& pharmacotherapie. 2018;99:411-421.

12. El-Agamy DS. Comparative effects of curcumin and resveratrol on aflatoxin B(1)-induced liver injury in rats. Archives of toxicology. 2010;84(5):389-396.

13. Reitman S, Frankel S. A colorimetric method for the determination of serum glutamic oxalacetic and glutamic pyruvic transaminases. American journal of clinical pathology. 1957;28(1):56-63.

14. Tietz NW, Burtis CA, Duncan P, et al. A reference method for measurement of alkaline phosphatase activity in human serum. Clinical chemistry. 1983;29(5):751-761.

15. Schmidt M, Eisenburg J. [Serum bilirubin determination in newborn infants. A new micromethod for the determination of serum of plasma bilirubin in newborn infants]. Fortschritte der Medizin. 1975;93(30):14611466.

16. Chow BF. The determination of plasma or serum albumin by means of a precipitin reaction. The Journal of biological chemistry. 1947;167(3):757-763.

17. Lowry OH, Rosebrough NJ, Farr AL, Randall RJ. Protein measurement with the Folin phenol reagent. The Journal of biological chemistry. 1951;193(1):265-275.

18. Larsen K. Creatinine assay by a reaction-kinetic principle. Clinica Chimica Acta. 1972;41:209-217.

19. Cohn C. Serum Urea Concentrations. JAMA. 1966;196(5):445-445.

20. Bancroft JD, Layton C. 10 - The hematoxylins and eosin. In: Suvarna SK, Layton C, Bancroft JD, eds. Bancroft's Theory and Practice of Histological Techniques (Eighth Edition). Content Repository Only!; 2019:126-138.

21. Snedecor G, Cochran W. Statistical methods. 8th ed. Ames, Iowa, USA: Iowa University Press; 1989.

22. Duncan DB. Multiple Range and Multiple F Tests. Biometrics. 1955;11(1):1-42.

23. Abe S. A case of ceftriaxone-associated biliary pseudolithiasis in an elderly patient with renal dysfunction. IDCases. 2017;9:62-64.

24. Haboob A. Cefixime-induced hepatotoxicity and acute renal failure: a case report. European Journal of Medical Case Reports. 2018:1.

25. Bjornsson ES. Drug-induced liver injury due to antibiotics. Scandinavian journal of gastroenterology. 2017;52(6-7):617-623.

26. Mujeeb M, Jalikar K. Pharmacokinetic study of cefpirome: fourth generation cephalosporin. Journal of Evolution of Medical and Dental Sciences. 2015;4:11834-11840.

27. Biner B, Oner N, Celtik C, et al. Ceftriaxone-associated biliary pseudolithiasis in children. Journal of clinical ultrasound : JCU. 2006;34(5):217-222. 
28. Bartkowska-Sniatkowska A, Jonczyk-Potoczna K, Zielinska M, Rosada-Kurasinska J. Adverse reaction to ceftriaxone in a 28-day-old infant undergoing urgent craniotomy due to epidural hematoma: review of neonatal biliary pseudolithiasis. Therapeutics and clinical risk management. 2015;11:1035-1041.

29. El-Sayed MGA, Elkomy AA, Aboubakr M. Hepatotoxic Evaluation in Albino Rats Exposed to Ceftriaxone. Asian J Pharm Biol Res 2011;1:145-150.

30. El-Safty Z, Elsayed M, Elbadawy M. hepato-renal adverse effects of amoxicilllin and doxycycline in rats. World J Pharm Pharm Sci. 2018;7(2):1-12.

31. Qadri I, Zeng X, Guo R, Koratala A. Acute interstitial nephritis and DRESS syndrome without eosinophilia associated with cefepime. BMJ case reports. 2017;2017.

32. Joob B, Wiwanitkit V. Oral cefepime-induced sterile pyuria and impaired renal function. Annals of Tropical Medicine and Public Health. 2016;9(6):419-420.

33. Soliman AM. Hepato-renal effects of cefotaxime in albino rats. 2015;7:312-315.

34. Jiang M, Yao J, Zhang LI, et al. Comparison of the influence on renal function between cefepime and cefpirome. Biomed Rep. 2016;4(1):40-44.

35. Abou-Samra S, El Ashmawy I, EL-Sawy A. Effects of Cefepime on Male Rats. Alex J Vet Science. 2012;37(1):55-69.

36. Mac K, Chavada R, Paull S, Howlin K, Wong J. Cefepime induced acute interstitial nephritis--a case report. BMC Nephrol. 2015;16:15-15.

37. El Maddawy K, Bogzil A. Adverse effects of cefotaxime sodium in comparison with ceftiofur sodium in male rats. International Journal of Pharmacy \& Life Sciences. 2015;6(3):4291-4303.

38. A E-S, A E-K, Abd Al-Wahed A. Protective Effect of Curcumin Against Adverse Effects of Meloxicam in Rats. Benha Veterinary Medical Journal. 2017;33(2):58-64.

39. Poapolathep S, Imsilp K, Machii K, Kumagai S, Poapolathep A. The Effects of Curcumin on Aflatoxin B1Induced Toxicity in Rats. Biocontrol science. 2015;20(3):171-177.

40. Azab A, Fetouh F, Albasha M. Nephro-protective effects of curcumin, rosemary and propolis against gentamicin induced toxicity in guinea pigs: Morphological and biochemical study. American Journal of Clinical and Experimental Medicine. 2014;2:28-35.

41. Manjunatha H, Srinivasan K. Protective effect of dietary curcumin and capsaicin on induced oxidation of lowdensity lipoprotein, iron-induced hepatotoxicity and carrageenan-induced inflammation in experimental rats. The FEBS journal. 2006;273(19):4528-4537.

42. Bao W, Li K, Rong S, et al. Curcumin alleviates ethanol-induced hepatocytes oxidative damage involving heme oxygenase-1 induction. Journal of ethnopharmacology. 2010;128(2):549-553.

43. Ahmad MM, Rezk NA, Fawzy A, Sabry M. Protective effects of curcumin and silymarin against paracetamol induced hepatotoxicity in adult male albino rats. Gene. 2019;712:143966.

44. Ismail A, Salem A. Renoprotective effect of curcumin on acetaminophen-induced nephrotoxicity in rats. 2016;8:773-779.

45. Ali BH, Al-Wabel N, Mahmoud O, Mousa HM, Hashad M. Curcumin has a palliative action on gentamicininduced nephrotoxicity in rats. Fundamental \& clinical pharmacology. 2005;19(4):473-477.

46. Mohajeri M, Sahebkar A. Protective effects of curcumin against doxorubicin-induced toxicity and resistance: A review. Critical reviews in oncology/hematology. 2018;122:30-51.

47. Shaterpour M, Shaki F, Ghasemi M, Jafari-Sabet M, Ziar A, Ataee R. The protective effect of curcumin against lithium-induced nephrotoxicity in rats. mazums-pbr. 2017;3(2):33-38. 